\title{
Karakter Ideal Konselor Multibudaya Berdasarkan Nilai Luhur Semar
}

\author{
Nora Yuniar Setyaputri \\ Prodi Bimbingan dan Konseling, Fakultas Keguruan dan Ilmu Pendidikan, Universitas Nusantara PGRI \\ Kediri, Jl. K.H. Ahmad Dahlan No. 76, Kediri, Jawa Timur, Indonesia 64112 \\ E-mail: setyaputrinora@gmail.com
}

Artikel diterima: 13 Mei 2016; direvisi 17 Juni 2017; disetujui 28 Juni 2017

\begin{abstract}
Nowadays a lot of counselor labeling their counselee which caused counselor's lack of multicultural insights. Labeling may have a poor impact on the counselor's decision in selecting counseling intervention strategies. The multicultural insights of counselors must be enhanced by building an ideal character in themselves. This ideal character is concerned with the understanding and behavior of counselors to respond the condition of heterogeneous counselees and how high the curiosity, interest and motivation of counselors to constantly add multicultural insights that they have. The noble values contained within Semar can be attributed to how the ideal character of multicultural counselors. This study aims to explain the ideal character of multicultural counselor taken from the noble value of Semar as well as linking the character with multicultural competence of counselor. This research uses qualitative approach of library research type. The ideal characteristics of multicultural counselors that can be formulated include: (1) religious; (2) neutral; (3) tolerance; (4) sincere; (5) discipline; (6) social care; (7) friendly; (8) fair; (9) honest; (10) supple; (11) democratic; and (12) curiosity.
\end{abstract}

Keywords: semar; ideal character; multicultural counselor

\begin{abstract}
Abstrak: Saat ini banyak konselor yang melakukan pelabelan karena kurangnya wawasan multibudaya konselor tersebut. Pelabelan yang dilakukan oleh konselor ini dapat berdampak kurang baik terhadap pemilihan strategi intervensi konselor terhadap konselinya. Wawasan multibudaya yang dimiliki konselor harus ditingkatkan dengan cara membangun karakter yang ideal pada diri mereka. Karakter ideal ini berkaitan dengan pemahaman dan perilaku konselor untuk menyikapi kondisi konseli yang heterogen serta seberapa tinggi rasa ingin tahu, minat maupun motivasi konselor untuk senantiasa menambah wawasan multibudaya yang mereka miliki. Nilai-nilai luhur yang terdapat di dalam diri Semar dapat dikaitkan dengan bagaimana karakter ideal konselor multibudaya. Penelitian ini bertujuan untuk menjelaskan karakter ideal konselor multibudaya yang diambil dari nilai luhur Semar serta mengkaitkan karakter tersebut dengan kompetensi multibudaya konselor. Penelitian ini menggunakan pendekatan kualitatif tipe library research. Karakter ideal konselor multibudaya yang dapat dirumuskan antara lain: (1) religius; (2) netral; (3) toleransi; (4) tulus; (5) disiplin; (6) peduli sosial; (7) bersahabat; (8) adil; (9) jujur; (10) luwes; (11) demokratis; dan (12) rasa ingin tahu.
\end{abstract}

Kata kunci: semar; karakter ideal; konselor multibudaya

Penelitian ini berawal dari pengamatan dan wawancara terhadap kurang lebih 10 mahasiswa kelas transfer di salah satu universitas swasta Kota Kediri yang mayoritas telah menjadi Guru Bimbingan dan Konseling (BK)/Konselor sekolah. Berdasarkan studi pendahuluan tersebut, diketahui bahwa dewasa ini guru BK marak melakukan pelabelan. Pelabelan yang terjadi misalnya konselor menganggap bahwa konseli yang mempunyai tato di tubuhnya bukanlah orang yang suci sehingga 
konselor tersebut enggan melakukan konseling kepada konseli tersebut. Kasus lain yang terjadi yaitu konselor melabeli konselinya dengan bandrol "super nakal" sehingga ketika menghadapi konseli tersebut rasa malas yang luar biasa muncul pada benak konselor. Pelabelan lain yang terjadi misalnya melabeli si konseli "anak jorok" karena bau badannya, serta banyak label lain karena perbedaan agama, ras, status sosial ekonomi dan lain sebagainya.

Pelabelan ini tentunya dapat memengaruhi bagaimana strategi intervensi selanjutnya yang dipilih oleh konselor untuk membantu mengentaskan permasalahan konseli. Berdasarkan fakta yang ada, konselor yang telah memberikan label kepada konseli cenderung kurang berkenan untuk memfasilitasi konseli agar terbebas dari masalahnya. Pelabelan yang dilakukan konselor dapat diakibatkan dari kurangnya wawasan multibudaya yang ada pada diri mereka, sedangkan keinginan untuk meningkatkan wawasan multibudaya yang ada pada diri konselor berkaitan dengan karakter yang dibangun dalam diri mereka.

Seringkali disebut-sebut dalam dunia pewayangan bahwa ada salah satu tokoh wayang yang mempunyai makna komplit dalam penggambaran kehidupan yaitu Semar. Tokoh wayang Semar begitu terkenal dengan pesan moral dan nilai-nilai yang diterapkan dapat menjaga keharmonisan antar umat di dalam kehidupan bermasyarakan yang heterogen (Izzati, 2017). Berdasarkan pernyataan tersebut dapat diketahui bahwa kinerja konselor erat pula hubungannya dengan kondisi masyarakat yang heterogen. Pelabelan yang muncul tersebut karena konselor belum dapat memahami perbedaan dari lingkungan konselinya yang amat heterogen. Mereka masih memakai kacamata dari budaya mereka sendiri untuk mengintervensi konseli-konseli mereka. Keharmonisan yang diidamkan dari kondisi konseli yang heterogen dapat didasarkan pada nilai-nilai kearifan lokal. Oleh karena itu nilai-nilai luhur yang terdapat di dalam diri Semar dapat dikaitkan dengan bagaimana karakter ideal seorang konselor multibudaya.

Semar dipilih sebagai model karena tokoh ini merupakan salah satu tokoh pewayangan yang tergolong unik dan mempunyai nilai-nilai luhur yang cukup dikenal dalam kehidupan masyarakat Indonesia. Kanjeng Sunan Kalijaga juga menggunakan tokoh ini dalam proses penyebaran Agama Islam di Pulau Jawa. Tokoh Semar adalah tokoh asli Jawa, dan tidak ada dalam referensi epos Ramayana, Mahabarata, dan Baratayudha di India (Tjahyadi, 2009). Keunikan dari sosok Semar ini didukung oleh perawakannya yang tampak ndeso, buruk rupa dan tampak tak menunjukkan kehebatan sama sekali. Namun dengan perawakannya yang seperti itu, nilai yang terkandung di dalamnya dapat dikatakan sangat luhur. Keluhuran nilai di dalam diri Semar ini juga dapat dijadikan contoh sebagai implementasi konsep manunggaling kawula Gusti. Manunggaling kawula Gusti merupakan persatuan antara hamba dengan Tuhan atau dalam istilah Arab disebut wahdatul wujud (Wahyudi, 2014).

Semar merupakan guru dari Pandawa yang tampak berwujud jelek namun ia merupakan simbol kebaikan. Sosok yang mempunyai kesaktian, kedalaman ilmu dan kearifan jiwa. Beberapa sebutan lain Semar adalah Saronsari, Ki Lurah Badranaya, Semar Badranaya, Nayantaka, Puntaprasanta, Janggan Asmarasanta, Bojagati, Wong Boga Sampir dan Ismaya (Notopertomo \& Jatirahayu, 2012). Dari beberapa nama tersebut yang paling sering disebut yaitu Semar atau Badranaya. Semar adalah sosok yang dapat bergaul dengan siapapun dan dari lapisan manapun.

Semar adalah lambang yang menjembatani manusia dan alam perwujudan kulturalnya dapat ditemukan dalam kearifan budaya, sebagaimana terlihat dari patokan normatif untuk "merendahkan diri" (andhap asor), dan hidup yang "cukup tetapi sederhana' (samadya), yang semuanya akan bermuara pada lestarinya keseimbangan lingkungan hidup, baik lingkungan sosial maupun lingkungan fisik, sebagaimana secara simbolik muncul sebagai dapat diatasinya gara-gara (keadaan disharmoni) oleh kehadiran Ki Lurah Semar dengan anak-anaknya (Tjahyadi, 2009). Semar berwatak sabar, jujur, ramah, suka humor, sederhana, tenang, rendah hati, tulus dan tidak munafik (Notopertomo \& Jatirahayu, 2012; Hermawan, 2013). Semar dalam tradisi Jawa juga disebut Badranaya (Bodronoyo). Bebadra artinya membangun sarana dari dasar, sedangkan Naya atau Nayaka dapat diartikan sebagai utusan mengrasul. Jadi, nama Badranaya dapat diartikan sebagai mengemban sifat membangun 
dan melaksanakan perintah Tuhan demi kesejahteraan manusia (Hermawan, 2013). Secara harfiah Semar juga dapat dimaknai sebagai sang penuntun makna kehidupan. Dapat disimpulkan bahwa sosok Semar adalah seorang abdi yang setia, pamomong, penasihat spiritual, teman bercengkrama dan penghibur pada saat permasalahan hadir pada diri seseorang.

Hal lain yang menarik dari diri Semar menurut Hermawan (2013) dapat dirinci sebagai berikut: (1) tubuhnya yang bulat merupakan simbol dari bumi, tempat tinggal umat manusia dan makhluk lainnya; (2) tangan kanannya ke atas, maknanya adalah sebagai pribadi tokoh semar hendak mengatakan simbol Sang Maha Tunggal. Tangan kiri di belakang, bermakna berserah total dan mutlak serta sekaligus simbol keilmuan yang netral namun simpatik; (3) Semar selalu tersenyum, tapi bermata sembab. Hal ini adalah simbol suka dan duka; (4) wajahnya tua tapi potongan rambutnya bergaya kuncung seperti anak kecil, sebagai simbol tua dan muda; (5) Semar berkelamin laki-laki, tapi memiliki payudara seperti perempuan, sebagai simbol pria dan wanita; (6) ia penjelmaan dewa tetapi hidup sebagai rakyat jelata dan posturnya yang tampak berdiri sekaligus jongkok, sebagai simbol atasan dan bawahan, bersatunya yang profan dan yang sakral, manunggaling kawula lan gusti; (7) rambut semar "kuncung" (jarwadasa=pribahasa jawa kuno) maknanya hendak mengatakan akuning sang kuncung, sebagai kepribadian pelayan. Semar sebagai pelayan mengejawantah melayani umat, tanpa pamrih untuk melaksanakan ibadah amaliah sesuai dengan sabda Ilahi; (8) Semar berjalan menghadap ke atas maknanya adalah dalam perjalanan anak manusia perwujudannya ia memberikan teladan agar selalu memandang ke atas (Sang Khaliq); (9) kain Batik Kawung yang dipakai Semar mencerminkan pribadi pemimpin yang yang mampu mengendalikan hawa nafsu serta menjaga hati nurani agar terdapat keseimbangan (adil) dalam perilaku kehidupan manusia; (10) kentut Semar adalah simbol kekuatan atau senjata yang ada pada diri manusia, asli berasal dari pribadi manusia itu sendiri dan bukan sesuatu dibuat orang lain untuk melindungi dirinya. Berdasarkan penelusuran kajian teoretik, kentut Semar ini adalah wujud suara rakyat yang dapat diserukan kepada para pemimpin. Namun, dalam tulisan ini kentut Semar lebih dimaknai sebagai potensi diri individu yang asli berasal dari dalam diri, dimana potensi diri ini dapat digunakan sebagai "senjata" untuk mengatasi permasalahan hidup; (11) ucapan spesial Semar yaitu mbergegeg ugeg-ugeg, hmel-hmel, sak ndulit langgeng yang dapat dimaknai daripada diam (mbergegeg), lebih baik berusaha untuk lepas (ugeg-ugeg) dan mencari makan (hmel-hmel), walaupun hasilnya sedikit (sakndulit), tapi akan terasa abadi (langgeng).

Adapun sifat Semar dari suluk wayang Ki Hadisugito antara lain Semar adalah figur yang selalu hati-hati, agar selalu halus dalam hidup ini (Endraswara, 2014). Semar biasanya keluar dalam suasana "eka balik", yaitu gara-gara menjelang orang bermimpi titi yoni, ada bau-bauan semerbak dari yoni. Saat itu ada seorang yang semedi, menyatukan tiga dunia yang tersinari rembulan. Petapa itu seperti sedang menghitung bintang Bima Sakti. Jadi, figur Semar itu selalu momong satria yang betah bertapa, selalu hati-hati hidupnya. Nuansa mistik kejawen memang muncul dari estetika Semar itu. Dari suluk ini terdapat dua hal terpenting dari Semar yaitu: (1) semangat kerendahan hati (anoraga); dan (2) berjiwa pamomong, sebagaimana Semar adalah dewa ngejawantah, selalu memayungi satria yang sukses.

Ajaran budi pekerti yang dapat dirumuskan oleh Setyaputri (2015) dari karakter Semar tersebut antara lain: (1) selalu sadar, mengingat, bersyukur dan berupaya melaksanakan perintah Tuhan Yang Maha Esa; (2) hendaknya kehidupan yang kita miliki ini adalah kehidupan yang bermanfaat bagi orang lain; (3) jangan melabeli orang lain berdasarkan kondisi fisiknya, yang tampak buruk tak selamanya buruk dan yang tampak baik tak selamanya baik, yang hitam belum tentu hitam dan yang putih belum tentu putih, ikan yang gemuk pun masih berduri sedangkan ikan yang kurus pun masih memiliki daging; (4) jangan mudah terkagum-kagum, jangan mudah menyesal, jangan mudah terkejut dan jangan manja dalam menghadapi kehidupan; (5) kemampuan diri bukanlah suatu hal yang harus disombongkan karena di atas langit masih ada langit; (6) senantiasa setia, tulus dan ikhlas dalam pengabdian baik kepada lembaga, suami ataupun orang tua; (7) berwibawalah tanpa mengandalkan kekuasaan/kekuatan/keturunan/kekayaan yang kita miliki; (8) anggaplah semua orang sama; (9) berlakulah adil, netral dan tidak menjadi provokator dalam konteks negatif; (10) senantiasa berupaya 
untuk menggali dan meningkatkan potensi diri karena berjuang dalam memperoleh cita-cita hidup tak perlu membawa massa dan memenangkan sesuatu tak harus merendahkan, mempermalukan bahkan menginjak kepala orang lain; (11) bekerja keras dan pantang menyerah dalam menjalani ujian dalam hidup.

Ajaran budi pekerti dari sosok Semar ini dapat digunakan sebagai sarana tercapainya cita-cita dalam hidup, karena ketercapaian cita-cita kehidupan bergantung pada diri kita sendiri. Tercapainya cita-cita hidup itu akan bergantung pada manusia itu sendiri dalam menggunakan kelengkapan hidup pemberian Tuhan, ialah: Pancaindera; Cipta-Rasa-Karsa; dan dua nafsu yang bertentangan, yaitu nafsu baik dan nafsu jahat (Soeharto \& Rukmana, 1991).

Keunikan sosok Semar ini merupakan buatan manusia untuk menggambarkan simbol orang bijak menurut sudut pandang manusia setelah ditandingkan dengan pemahaman mereka mengenai Tuhan dan semua makhluk ciptaannya. Buatan manusia yang diperuntukkan kepada manusia, berisi gambaran-gambaran mengenai bagaimana kebijaksanaan dalam versi manusia (Setyaputri, 2015). Dengan alasan ini nilai-nilai tersebut lebih dapat masuk ke dalam kehidupan sosial masyarakat dari berbagai lapisan, entah etnis atau latar belakang kepercayaannya. Hal ini berkaitan dengan sistem sosial budaya. Dimana sistem sosial budaya sangat memengaruhi bagaimana kepribadian seseorang yang ada di dalamnya.

Semar merupakan simbol orang bijak dalam versi manusia, tetap pada kaidah manusia yang juga tidak luput dari kesalahan. Pendapat tersebut didapat dari cerita Semar yang dulunya tinggal di kahyangan kemudian diturunkan ke bumi karena masih memiliki ambisi dan keserakahan untuk memperoleh tahta. Demikianlah seorang konselor, konselor bukan diciptakan sebagi pribadi yang terhindar dari kesalahan/dosa (maksum), namun senantiasa berusaha untuk meminimalisasi kesalahan demi mencapai cita-cita hidup termasuk profesionalisme sebagai seorang konselor. Berdasarkan pemaparan mengenai Semar dan bagaimana karakter ideal seorang konselor multibudaya dalam menjalankan tugasnya maka dalam artikel ini akan dideskripsikan mengenai karakter ideal konselor multibudaya yang diambil dari tokoh wayang Semar serta mengkaitkannya dengan kompetensi multibudaya konselor.

\section{METODE}

Penelitian ini dilaksanakan dengan menggunakan pendekatan kualitatif tipe library research. Tipe ini dipilih karena sebagian besar sumber data lebih mengutamakan sumber dari bahan pustaka. Oleh karena sumber data lebih mengutamakan sumber dari bahan pustaka, maka penelitian ini dapat dikategorikan sebagai penelitian kualitatif deskriptif perpustakaan, penelitian bibliografis atau ada yang mengistilahkan penelitian non reaktif karena sumber data lebih mengutamakan sumber referensi teoritik dari perpustakaan dan sumber dokumentasi (Hambali, 2016).

Karakteristik tipe penelitian ini salah satunya adalah melibatkan identifikasi dan penempatan sumber yang menyediakan informasi faktual atau pendapat pribadi/pakar mengenai pertanyaan penelitian (George, 2008). Data yang diperoleh dari sumber kepustakaan tersebut dianggap menjadi data empirik. Data tersebut kemudian dipilah-pilah sesuai dengan permasalahan apa yang diangkat dalam penelitian, baik sebagai data primer maupun data sekunder. Sumber data primer adalah berupa buku-buku yang mengkaji tokoh wayang Semar serta jurnal-jurnal penelitian yang mengangkat tokoh wayang Semar, sedangkan sumber data sekunder diperoleh dari artikel-artikel media online yang membahas tokoh Semar. Logika proses penelitian perpustakaan (library research) adalah pergerakan dari apa yang ada pada apa yang layak digunakan (George, 2008).

Penelitian ini menggunakan 9 tahap penelitian kepustakaan yang dirinci oleh George (2008), yaitu: (1) memilih topik umum; (2) melibatkan imajinasi; (3) merumuskan satu atau beberapa pertanyaan sebagai hasil dari brainstorming tentang topik yang diangkat; (4) mengembangkan sebuah rencana dan strategi penelitian; (5) mendiskusikan alat referensi dan mencari basis data; (6) mengidentifikasi dan mendapatkan sumber; (7) mengevaluasi sumber berdasarkan pertanyaan 
penelitian; (8) mendalami pemahaman/wawasan berdasarkan pada refleksi; dan (9) merangkai pernyataan tesis berdasarkan pemahaman.

\section{HASIL}

Dari pemaparan mengenai Semar dan kajian teoretis mengenai kompetensi multibudaya dapat dirumuskan 12 karakter ideal konselor multibudaya, antara lain: (1) religius, karakter ini diambil dari makna nama Badranaya dan simbol tangan kanan menunjuk ke atas serta ajaran budi pekerti dari Semar yang mengajarkan bahwa kita senantiasa harus selalu sadar, mengingat, bersyukur dan berupaya melaksanakan perintah Tuhan Yang Maha Esa; (2) netral, karakter ini diambil dari makna simbol tangan kiri Semar yang berada di belakang sebagai lambing keilmuan yang netral serta ajaran budi pekerti Semar yang menyatakan bahwa berlakulah adil, netral dan tidak menjadi provokator dalam konteks negatif; (3) toleransi, diwujudkan dengan menerima konseli tanpa melabeli. Karakter ini diambil dari postur keseluruhan Semar yang nampak buruk namun simbol kebaikan serta ajaran budi pekerti Semar yang mengajarkan bahwa jangan melabeli orang lain berdasarkan kondisi fisiknya, yang tampak buruk tak selamanya buruk dan yang tampak baik tak selamanya baik, yang hitam belum tentu hitam dan yang putih belum tentu putih, ikan yang gemuk pun masih berduri sedangkan ikan yang kurus pun masih memiliki daging; (4) tulus dalam memberikan pelayanan BK terhadap konseli. Karakter ini diambil dari makna rambut Semar kuncung atau jarwadasa, sesuai artinya akuning sang kuncung, sifat tulus Semar, serta profesi Semar yang bertindak sebagai pamomong Pandawa, penasihat spiritual dan teman bercengkrama di kala susah serta ajaran budi pekerti Semar yang menyatakan bahwa kita hendaknya senantiasa setia, tulus dan ikhlas dalam pengabdian baik kepada lembaga, suami ataupun orang tua; (5) disiplin, karakter ini diambil dari makna Semar yang berjalan menghadap ke atas. Dapat ini diwujudkan dengan mematuhi aturan/ kode etik yang ada dan memberikan contoh yang baik; (6) peduli sosial, karakter ini diambil dari makna Semar adalah simbol atasan dan bawahan dan ajaran budi pekerti Semar yang mengajarkan bahwa hendaknya kehidupan yang kita miliki ini adalah kehidupan yang bermanfaat bagi orang lain. Diwujudkan dengan menerima konseli dari latar belakang budaya manapun; (7) bersahabat, karakter ini diambil dari pergaulan Semar yang tidak membedakan dari lapisan manapun dan ajaran budi pekerti Semar yang menyatakan bahwa kita hendaknya menganggap semua orang sama; (8) adil dalam memberikan pelayanan BK terhadap konseli. Karakter ini diambil dari Kain Batik Kawung yang dipakai Semar serta ajaran budi pekerti Semar yang menyatakan bahwa berlakulah adil, netral dan tidak menjadi provokator dalam konteks negatif; (9) jujur, karakter ini diambil dari sifat bawaan Semar yang jujur dan tidak munafik; (10) luwes/tidak kaku dalam menyikapi budaya konseli yang berbeda. Karakter ini diambil dari sifat Semar yang sabar, ramah, suka humor, sederhana, tenang dan rendah hati; (11) demokratis, karakter ini diambil dari makna kentut Semar ini adalah wujud suara rakyat yang dapat diserukan kepada para pemimpin serta ajaran budi pekerti Semar yang menyatakan bahwa berwibawalah tanpa mengandalkan kekuasaan/kekuatan/ keturunan/kekayaan yang kita miliki; (12) rasa ingin tahu, diwujudkan dengan memanfaatkan dan meningkatkan potensi diri. Karakter ini diambil dari makna kentut Semar dan ungkapan yang sering dikeluarkan oleh Semar yaitu mbergegeg ugeg-ugeg, hmel-hmel, sak ndulit langgeng serta ajaran budi pekerti Semar yang menyatakan bahwa kita hendaknya senantiasa berupaya untuk menggali dan meningkatkan potensi diri. Seorang konselor senantiasa memanfaatkan dan meningkatkan potensi diri melalui berbagai macam proses, misalnya studi lanjut, pelatihan dan perluasan wawasan diri. Wawasan ini baik tentang budayanya sendiri, budaya konseli dan bagaimana cara menjembatani perbedaan budaya yang membentuk mereka agar proses konseling dapat terlaksanakan dengan baik. Keprofesionalan seorang konselor multibudaya akan semakin tampak jika semakin kuat "kentutnya" atau potensi dirinya.

Dua belas karakter yang telah disebutkan dapat digunakan untuk mengoperasionalkan kompetensi multibudaya yang harus dikuasai oleh konselor multibudaya. Konseling yang efektif harus mempertimbangkan pengaruh budaya terhadap fungsi konseli (Corey, 2009; Corey, 2013). Maksudnya, konselor yang efektif dalam melakukan konseling adalah seorang konselor yang 
mengerti bagaimana keadaan budayanya sendiri, kondisi konselinya dan kondisi lingkungan yang menjadi bagian dari mereka. Pemahaman dan pengakuan adanya perbedaan budaya ini dapat konselor lakukan sebagai upaya peningkatan kualitas diri baik melalui segi pendidikan, pelatihan, praktik bahkan penelitian (Constantine \& Sue, 2005). Seorang konselor memiliki tiga dimensi kompetensi multibudaya, yaitu: (1) kepercayaan dan sikap (beliefs and attitude); (2) pengetahuan (knowledge); (3) keterampilan (skill) (Sue, Arredondo \& McDavis, 1992).

Kepercayaan dan sikap (beliefs and attitude), konselor yang efektif mengetahui dan memahami adanya warisan budaya yang memengaruhi mereka, mempelajari dan mengerti latar belakang budaya konselinya serta tidak memaksakan nilai-nilai dan harapan mereka terhadap konselinya.

Pengetahuan (knowledge), konselor yang efektif mengetahui dan memahami adanya warisan budaya yang memengaruhi mereka, mempelajari dan mengerti latar belakang budaya konselinya serta tidak memaksakan nilai-nilai dan harapan mereka terhadap konselinya.

Keterampilan (Skill), konselor yang efektif memiliki keterampilan tertentu dalam bekerja pada populasi yang berbeda. Konseling multibudaya akan bernilai lebih apabila konselor menggunakan metode dan strategi serta gambaran tujuan yang konsisten dengan pengalaman hidup dan nilai budaya konseli.

Kompetensi Konselor dalam ranah multibudaya merupakan suatu hal yang perlu untuk dimiliki agar dapat menjadi seorang Konselor yang efektif. Kompetensi multibudaya bukan sesuatu hal yang muncul tiba-tiba, namun merupakan suatu proses yang perlu dilatihkan dan dibiasakan pada diri Guru BK/Konselor tersebut. Pemaparan ini senada dengan pendapat ahli sebagai berikut.

Konselor yang efektif adalah konselor yang mengerti keadaan budayanya sendiri, kondisi klien mereka, dan sistem sosiopolitik yang merupakan bagian dari mereka. Pengertian ini dimulai dari kesadaran konselor tentang nilai budaya, prasangka, dan sikap yang mereka pegang. Bagian besar menjadi konselor yang kompeten dalam perbedaan budaya ini meliputi tantangan nilai yang kita pegang dan bagaimana nilai tersebut memengaruhi praktik kita dengan perbedaan budaya yang ada pada diri klien. Selanjutnya, untuk menjadi praktisi yang kompeten dalam hal ini bukan sesuatu yang hadir bersamaan dan untuk semua, melainkan proses yang berkelanjutan (Corey, 2013).

Salah satu cara untuk melatih dan membiasakan pada diri konselor agar kompetensi multibudaya tersebut ada pada diri seorang konselor adalah peka terhadap budaya dan memiliki karakter yang mendukung hal tersebut. Karakter ideal konselor multibudaya yang telah dirumuskan dari nilai luhur Semar tersebut dapat dikaitkan dengan ketiga kompetensi multibudaya di atas. Hal ini berkaitan dengan karakter apa saja yang dapat masuk dalam masing-masing ranah kompetensi tersebut, misalnya: (1) kompetensi kepercayaan dan sikap, karakter yang dapat dimasukkan dalam kompetensi ini antara lain: (a) religius; (b) tulus; (c) toleransi; (d) adil; dan (e) jujur; (2) kompetensi pengetahuan, karakter yang dapat dimasukkan dalam kompetensi ini antara lain: (a) netral; (b) disiplin; dan (c) rasa ingin tahu; (3) kompetensi keterampilan, karakter yang dapat dimasukkan dalam kompetensi ini antara lain: (a) peduli sosial; (b) bersahabat; (c) luwes; dan (d) demokratis.

\section{PEMBAHASAN}

Seiring semakin berkembangnya zaman, nilai-nilai luhur Semar semakin hilang dari dalam diri individu, tidak menutup kemungkinan diri seorang konselor. Jika dikaitkan dengan pentingnya keberadaan Bimbingan dan Konseling saat ini, konselor mempunyai tempat yang sentral sebagai praktisi di lapangan. Menarik tampaknya jika seorang konselor memiliki karakter seperti yang tergambar di dalam diri Semar. Dimana nantinya konselor tersebut baik dalam kehidupan pribadisosialnya atau saat pemberian layanan BK baik di sekolah maupun di luar sekolah membawa nilainilai luhur yang terkandung di dalam diri Semar tersebut. Selain itu, seorang konselor sangat penting memiliki wawasan multibudaya dalam praktik konseling.

Pemahaman/wawasan konselor dalam ranah multibudaya dirasa sangat penting karena budaya yang melatarbelakangi seseorang dapat memengaruhi cara berpikir mereka mengenai suatu hal, bagaimana perilaku sosial mereka dalam kelompok budaya yang sama (ingroup) dan 
kelompok budaya yang berbeda (outgroup), bagaimana seseorang berkomunikasi serta bagaimana mengekspresikan emosi mereka. menyatakan bahwa adanya budaya terkait dengan pengakuan siapa diri kita dan bagaimana kita berhubungan dengan orang-orang di sekitar kita (Cross \& Papadopoulos, 2001). Budaya adalah dasar dari suatu negara (Matsumoto \& Juang, 2016) .

Miss communication mengenai bahasa dan komunikasi nonverbal bisa terjadi karena kurangnya pemahaman pada diri konselor mengenai hal itu dan mereka juga tidak berusaha mencari tahu serta menambah wawasannya mengenai budaya setempat. Seringkali peng"aku"an mengenai budaya konselor sendiri juga menjadi benteng dalam proses konseling. Perlu diketahui bahwa dalam konseling terdapat nilai positif dan bersifat universal supaya bisa diterima siapa saja, bukan nilainilai minoritas yang hanya bisa diterima oleh beberapa pihak saja.

Kurangnya objektivitas konselor ini misalnya mengenai permasalahan etnis, perbedaan agama antara konselor dan konseli, status sosial dan lain sebagainya. Misalnya dalam suatu kasus tertentu seorang konselor enggan menerima konselinya karena melihat ada tato di salah satu bagian tubuh konseli tersebut. Konselor harus berhati-hati dengan warisan ras kulturalnya sendiri dan memahami bagaimana warisan tersebut bisa memengaruhi sikap-sikap, keyakinan-keyakinan, nilai-nilai, prasangka-prasangka, dan keberatsebelahan dalam dirinya (Geldard \& Geldard, 2011). Untuk menjadi terapis seseorang harus belajar mengenai sistem nilai yang ada pada dirinya sendiri, faktor pendukung dan penghambat ketika praktik serta dapat mengatasi isu-isu penting berkaitan dengan keluarga, budaya, jenis kelamin dan etika (Cross \& Papadopoulos, 2001). Dapat disimpulkan bahwa konselor juga dapat menjadi terapis dalam konteks orang-orang normal.

Wawasan multibudaya sangat penting agar dapat memberikan pelayanan konseling secara efektif kepada semua sasaran layanan yang beranekaragam (Wibowo, 2015). Oleh karena itu, wawasan multibudaya ini dapat digunakan konselor untuk memprediksi bagaimana identitas konselinya sebagai dasar strategi intervensi selanjutnya. Kurangnya wawasan konselor dalam ranah multibudaya dapat diakibatkan karena karakter yang mereka bangun di dalam dirinya. Dengan dimiliki dan dikembangkannya kedua belas karakter ideal konselor multibudaya yang diambil dari nilai luhur Semar tersebut, pelabelan yang dilakukan oleh konselor terhadap konselinya dapat diminimalisasi serta pelaksanaan konseling multibudaya dapat berjalan dengan efektif.

\section{SIMPULAN}

Berdasarkan hasil penelitian ini, terdapat 12 karakter ideal konselor multibudaya yang dapat dirumuskan dari nilai luhur semar, yaitu: (1) religius; (2) netral; (3) toleransi; (4) tulus; (5) disiplin; (6) peduli sosial; (7) bersahabat; (8) adil; (9) jujur; (10) luwes; (11) demokratis; dan (12) rasa ingin tahu. Untuk dapat menjadi konselor multibudaya yang profesional serta dapat memenuhi kompetensi multibudaya, seyogyanya konselor dapat membangun kedua belas karakter tersebut. Penanaman karakter ini dapat dimulai sedini mungkin, dibiasakan dalam kehidupan sehari-hari, atau sekurang-kurangnya dapat dimulai semenjak menjadi mahasiswa Strata 1 BK. Hal ini dimaksudkan agar nantinya ketika keluar dari bangku perkuliahan dan memasuki kehidupan kerja yang nyata, karakter-karakter tersebut dapat semakin menguat.

Mengacu pada hasil penelitian ini ada beberapa saran yang diajukan. Pertama terhadap pengampu kebijakan Program Studi BK seyogyanya menyusun kebijakan berbasis kearifan lokal (nilai-nilai luhur Semar) agar internalisasi karakter Semar tersebut dapat dibiasakan pada kalangan civitas akademika Prodi BK. Kedua terhadap akademisi Program Studi BK seyogyanya menambah media pembelajaran baik berupa permainan, panduan, paket pelatihan maupun buku ajar yang memuat nilai-nilai luhur Semar sebagai sarana pengembangan karakter calon konselor multibudaya misalnya pada matakuliah Sosioantroplogi BK, Konseling Multibudaya, dan Pengembangan Pribadi Konselor. Ketiga kepada mahasiswa S1 BK dapat mengambil karakter Semar tersebut sebagai bahan penelitian lanjutan atau dalam bentuk penulisan skripsi. Keempat kepada para Konselor dapat menjadikan Semar sebagai model dalam pelaksanaan konseling berbasis multibudaya di tempat kerja mereka agar pelabelan yang terjadi dapat diminimalisasi. 


\section{DAFTAR RUJUKAN}

Bayuadhy, G. (2014). Wong Sugih Mati Keluwen, Falsafah Kearifan Jawa di Tengah Zaman Edan. Yogyakarta: DIVA Press.

Constantine, M. G., \& Sue, D. W. (Eds.). (2005). Strategies for Building Multicultural Competence in Mental Health and Educational Settings. Canada: John Wiley \& Sons.

Corey, G. (2009). Theory and Practice of Counseling and Psychotherapy, Eight Edition. Belmot, CA: Brooks/Cole.

Corey, G. (2013). Theory and Practice of Counseling and Psychotherapy, Ninth Edition. Belmot, CA: Brooks/Cole.

Cross, M.C., \& Papadopoulos, L. (2001). Becoming a Therapist : A Manual for Personal and Professional Development. USA: by Taylor and Francis Inc.

Endraswara, S. (2014). Politik Gaya Sengkuni dan Estetika Semar Kajian Antropologi Sastra Terhadap Pemilu Legislatif. Masyarakat, Kebudayaan dan Politik, 27(4), 195-205. doi:http:// dx.doi.org/10.20473/mkp.V27I42014.184-195

Geldard, K., \& Geldard, D. (2011). Keterampilan Praktik Konseling: Pendekatan Integratif. Jakarta: Pustaka Pelajar.

George, M.W. (2008). The Element of Lybrary Research. United Kingdom: Princeton University Press.

Hambali, IM. (2016). Perspektif "Family System Intervency" Untuk Proteksi Karakter Kebajikan Siswa SMA. Jurnal Kajian Bimbingan dan Konseling, 1(1), 12-18. Diambil dari http://journal2. um.ac.id/index.php/jkbk/article/view/627

Hermawan, D. (2013). Semar dan Kentut Kesayangannya. Yogyakarta: DIVA Press.

Izzati, A. (2017). Nilai-nilai Konstruk Harmoni Perspektif Tokoh Wayang Semar. FIKRAH, 4(2), 261-275. doi:http://dx.doi.org/10.21043/fikrah.v4i2.1631

Matsumoto, D., \& Juang, L. (2016). Culture and psychology. Nelson Education.

Notopertomo, M., \& Jatirahayu, W. (2012). 51 Karakter Tokoh Wayang Populer. Klaten: PT Hafamira.

Setyaputri, N.Y. (2015). Koneksitas Nilai-nilai Luhur di dalam Semar (Badranaya) terhadap Ciriciri Konselor Multibudaya dan Praktik Konseling Multibudaya. In S. Sugiharto (Ed.) UNNES: Seminar Nasional Konseling Berbasis Multikultural (pp. 92). Semarang: Fakultas Ilmu Pendidikan UNNES

Soeharto \& Rukmana, H. (1991). Butir-butir Budaya Jawa, Hanggayuh Kasampurnaning Hurip Berbudi Bawaleksana Ngudi Sejatining Becik. Jakarta: Yayasan Purna Bhakti Pertiwi.

Sue, D. W., Arrendondo, P., \& McDavis, R. J. (1992). Multicultural Counseling Competencies and Standards: A Call to the Profession. Journal of Counseling \& Development, 70(4), 477-486. https://doi.org/10.1002/j.1556-6676.1992.tb01642.x

Tjahyadi, S. (2016). Dekonstruksi Pemahaman Budaya Jawa tentang Hakikat dan Hubungan Kawula-Gusti pada Lakon Wayang "Semar Kuning". Jurnal Filsafat, 19(2), 103-125. https:// doi.org/10.22146/jf.3441

Wahyudi, A. (2014). Bersatu Manunggaling Kawula Gusti. Jogjakarta: DIVA Press.

Wibowo, M. E. (2015). Perspektif Konseling Multikultural dalam Masyarakat Indonesia. Paper presented at Seminar Nasional Perspektif Konseling Berbudaya Multikultural, Semarang, Jawa Tengah 